\title{
VENTILATION AND CHEMOREFLEXES DURING ENFLURANE SEDATION AND ANAESTHESIA IN MAN
}

\author{
R.L. KNilL, P.H. Manninen and J.L. Clement
}

ENFLURANE is a potent ventilatory depressant in the absence of surgical stimulation ${ }^{1,2}$ and perhaps the most potent among the inhaled anaesthetics. ${ }^{3}$ Its effect on those refiexes central to the metabolic regulation of ventilation. the ventilatory responses to carbon dioxide, hypoxia and variations of arterial hydrogen ion concentration is not known in man. The activity of these reflexes is of particular interest to anaestherists. as hypercapnia, hypoxia and metabolic acidosis are well known complications of both anaesthesia and the immediate post-anaesthetic state. Accordingly, we measured ventilatory responses to experimental hypercarbia and hypoxaemia in fit young subjects while fully awake, during sedation with sub-anaesthetic concentrations and during anaesthesit with enflurane $(0.1$ and 1.1 $\mathrm{MAC}$ ). In addition. we studied responses to a small intravenous bolus of doxapram. Both sedaltion and anuesthesia reduced responses to all three chemical stimuli. with the greater impact on responses to hypoxaemin and doxapram. which are those mediated by peripheral chemoreceptors.

\section{Methods}

The subjects studied during sedation were anaesthetic residents, anaesthetists and respiratory technologists; those studied during anaesthesia were patients who had agreed to an extra period of anaesthesia before an elective surgical procedure (usually multiple dental extractions). There were 23 subjects altogether, eight males and 15 females. whose ages ranged from 18 to 30 years and whose mean weight and height were $65.0 \pm 9.8 \mathrm{~kg}$ and $168 \pm 6 \mathrm{~cm}$ respectively (mean \pm S.D.). All were non-smokers and in excellent

R.L. Knill, M.D. F.R.C.P.(C), P.H. Manninen. M.D. and J.L. Clement, R.N.. Department of Anaesthesia. University Hospital, University of Western Ontario, London. Canada.

This work was supported by The Medical Research Council of Canada Development Grant 150 and by a Grant from Ohio Medical Products. Canada.

Address reprint requests to Dr. R.L. Knill. Department of Anaesthesia, University Hospital, 339 Windermere Road. London, Ontario, Canada. N6A 5A5. health. No subject took regular medication. Each signed a consent form approved by an Ethics Review Committee of the University of Western Ontario.

The detailed methods were similar to those employed previously for halothane studies, ${ }^{4}$ For anaesthesia, each unpremedicated subject was positioned supine. We induced anaesthesia with enflurane in oxygen. frequently supplemented by intravenous thiopentone $1-2 \mathrm{mg} \cdot \mathrm{kg}^{-1}$, during the excitement phase. Following neuromuscular paralysis with intravenous succinylcholine I $\mathrm{mg} \cdot \mathrm{kg}^{-1}$, the upper trachea was sprayed with lidocaine four per cent and then intubated with an 8 or $9 \mathrm{~mm}$ cuffed orotracheal tube. Breathing spontaneously. each subject inhaled enfurane in oxygen from a non-rebreathing circuit. with the vaporizer concentration set to achieve an endtidal value equivalent to 1.1 or 1.5 MAC. Inhalation continued for 45 minutes. to achieve reasonably steady anaesthetic and respiratory states as assessed by continuous monitoring of ventilation and end-tidat concentrations of enflurane and carbon dioxide. During this period subjects received an intravenous infusion of dextrose five per cent in 0.2 per cent saline. up to $700 \mathrm{ml}$. To estimate $\mathrm{PaCO}_{2}$. blood was drawn anaerobically into a previously heparinized syringe from a needle placed either in the radial artery or in a free-flowing cutaneous vein of the dorsum of the hand. 'The sample was capped, placed in ice and analyzed within one hour. We next recorded a one-minute period of unstimulated ventilation and noted the end-tidal concentration of carbon dioxide.

Progressive hypercarbia was created by the rebreathing technique of Read ${ }^{\circ}$ employing a closed circuit primed with carbon dioxide 7.5 to 9 per cent, enflurane in a concentration appropriate to maintaining anaesthetic depth constant and the remainder oxygen. The tracheal tube was connected to the Read circuit at the end of an expiration. We immediately equilibrated the alveolar. mixed venous and circuit carbon dioxide levels by inflating the lungs three to five limes with large volumes from the circuit. ${ }^{7}$ Then, as the subject 353

Canad. Anaesth. Soc. J., vol. 26, no. 5, September 1979 
breathe, the carbon dioxide levels of both circuit and subject progressively increased. The test was terminated at a circuit carbon dioxide concentration of 9.5 to 10.5 per cent, which was usually attained within five or six minutes. The progressive increase of circuit carbon dioxide observed during this test is believed to represent nearly identical changes in blood and brain carbon dioxide levels. ${ }^{7}$

The subject next inhaled enflurane in oxygen from the non-rebreathing circuit for a sufficient time (approximately five minutes) to re-establish control values of ventilation and PET cog. Progressive hypoxaemia was then induced by the method of Weil. ${ }^{8}$ We gradually replaced inhaled oxygen with air and then with air and nitrogen, so that end-tidal oxygen tension decreased to 5.3-6.0 $\mathrm{kPa}$ (40-45 tors) over an 8- to 10-minute period. During this test end-tidal carbon dioxide concentration was monitored continuously, and 100 per cent carbon dioxide was added to inspired gas when necessary to maintain end-tidal isocapnia.

After recovery from this stimulus and while again hyperoxic, three subjects received an intravenous bolus of doxapram $0.4 \mathrm{mg} \cdot \mathrm{kg}^{-1}$ as another test of ventilatory chemosensitivity. ${ }^{9}$

During and after all tests we monitored and recorded radial pulse rate, electrocardiogram lead II. systemic arterial pressure, inspired ventilatory volumes and end-tidal concentrations of enflurane, oxygen and carbon dioxide.

For enflurane sedation, subjects sat in a comfortable chair, breathing through a mouthpiece with the nose occluded by a clip. They inhaled small concentrations of enflurane $(0.3$ to 0.5 per cent) in oxygen for at least 20 minutes to achieve and maintain a steady end-tidal concentration equivalent to 0.l MAC. With sedation continuing. tests were performed as in the anaesthetized state. except that the Read circuit was primed with seven per cent carbon dioxide, equilibration with the circuit was attained by three to five spontaneous large breaths and the test progressed to a carbon dioxide concentration of 8.5 per cent.

Studies of the awake state were also conducted with subjects seated and breathing through a mouthpiece. Details of the carbon dioxide re. sponse test were the same as in the sedated state. In each subject who had been anaesthetized, we attempted to measure ventilation and the response to hypoxaemia at or as close as possible to the elevated end-tidal carbon dioxide tension which had been present during his anaesthetic. This level was re-created by adding carbon dioxide to inspired gas for a 10- to 12-minute equilibration period.

In all tests, exhaled gases were sampled continuously close to the airway and analyzed by a Perkin-Elmer \# 1000 mass spectrometer, which was regularly calibrated with Scott or Canadian Liquid Air specialty gases. Values of end-tidal carbon dioxide, oxygen and enflurane were the end-tidal plateau concentrations read from a time-based recorder, Blood $\mathrm{PCO}_{2}$ was measured by a Radiometer Copenhagen BMS 3 system, calibrated daily with tonometered blood. Inspired flows and volumes were determined by pneumotachography, calibrated and employed as previously described. ${ }^{4}$ Values of instantaneous ventilation and tidal volume were the average of at least three consecutive breaths and were converted to BTPS.

Carbon dioxide responses are reported as the slope of the least squares linear regression of the ventilation: $\mathrm{PCO}_{2}$ relationship. Hypoxaemic responses are represented by two values - the $\Delta \dot{V}_{I_{45}}$, which is the increment in ventilation from hyperoxaemia to hypoxaemia $\left(\mathrm{PET}_{\mathrm{O}_{2}} 6.0 \mathrm{kPa}\right)(45$ torr) and " $A$ " - a shape parameter of the entire hypoxaemic response, which assumes a hyperbolic relationship between ventilation and $\mathrm{PET}_{\mathrm{O}_{2}}{ }^{8}$ Doxapram responses are the maximum increment in ventilation during the first minute following bolus injection."

Statistical evaluation was by two tailed t-lests for paired data. We considered $p$ values of 0.05 or less as indicative of a significant difference between awake and enflurane data.

\section{RESULTS}

There were no important complications during or after the study. Enflurane 0.1 MAC produced a state of pleasant drowziness closely akin to that previously observed with halothane 0.1 MAC. ${ }^{10}$ Sedation altered neither arterial blood pressure nor pulse rate. Anaesthesia reduced systolic pressure modestly (average drop $2.7 \mathrm{kPa}$ [20 torr], from highest to lowest systolic value) while increasing heart rate slightly (average 4 beats/min). The heart rate and blood pressure responses to hypoxaemia and hypercarbia in awake, sedated and anaesthetized states were similar to those previously described."

Sedation (0.I MAC) and anaesthesia ( 1.1 and 1.5 MAC) reduced ventilation in a dosedependent fashion (Table 1, Figure 1). The effect of sedation was only slight, but the effect of antesthesia was marked. With reduction in ven- 
TABLE I

Ventilation and Responses to Stimult During Enflurane Sedation and Anaethesia

\begin{tabular}{|c|c|c|c|c|}
\hline & \multicolumn{2}{|c|}{$0.1 \mathrm{MAC}(\mathrm{n}=10)$} & \multicolumn{2}{|c|}{$1.1 \mathrm{MAC}(\mathrm{n}=10)$} \\
\hline & Awake & Sed'n. & Awake & Anaes. \\
\hline $\begin{array}{l}\text { VENTILATION } \\
\text { (L/min) } \\
\mathrm{PET}_{\mathrm{CO}_{2}} \text { (torr) } \\
\mathrm{Pa}_{\mathrm{CO}_{2}} \text { (torr) }\end{array}$ & $\begin{array}{r}8.0 \pm 0.3 \\
37 \pm 0.8 \\
38 \pm 1.1\end{array}$ & $\begin{array}{l}6.9 \pm 0.6 \dagger \\
37 \pm 0.8 \\
38 \pm 1.1\end{array}$ & $\begin{aligned} 16.6 \pm 1.7 \\
43 \pm 1.2^{*} \\
43 \pm 1.6^{*}\end{aligned}$ & $\begin{aligned} 3.5 & \pm 0.2 \dagger \\
47 & \pm 1.4 \\
54 & \pm 2.1\end{aligned}$ \\
\hline $\begin{array}{l}\mathrm{CO}_{2} \text { RESPONSE SLOPE } \\
\text { (L/min/torr) }\end{array}$ & $2.6 \pm 0.2$ & $2.0 \pm 0.3 \dagger$ & $1.9 \pm 0.2$ & $0.7 \pm 0.1 \dagger$ \\
\hline $\begin{array}{l}\text { HYPOXEMIC RESPONSE } \\
\Delta \dot{V}_{\mathrm{I}_{45}}(\mathrm{~L} / \mathrm{min}) \\
\text { "A" (L" torr } / \mathrm{min})\end{array}$ & $\begin{array}{l}7.8 \pm 2.5 \\
132 \pm 30\end{array}$ & $\begin{array}{c}3.5 \pm 1.0 \dagger \\
50 \pm 12 \dagger\end{array}$ & $\begin{array}{c}13.7 \pm 3.4 \\
273 \pm 83\end{array}$ & $\begin{aligned} 0.4 & \pm 0.3 \dagger \\
5 & \pm 5 \dagger\end{aligned}$ \\
\hline
\end{tabular}

Values are mean \pm S.E.M.

Ventilation and Hypoxemic Responses in each state measured at $\mathbf{P C O}_{2}$ indicated.

${ }^{*} \mathrm{PCO}_{2}$ increased by inhaling $\mathrm{CO}_{2}$.

†Significantly different from awake $(\mathrm{p}<0.05)$.

tilation, tidal volumes were smaller and breathing frequency increased (Figure 1). For awake, 0.1, 1.1 and 1.5 MAC states, values of ventilation (mean \pm S.E.M.) were $8.0 \pm 0.3,6.9 \pm 0.6,3.5 \pm$ 0.2 and $2.9 \pm 0.5$ litres per minute respectively. Tidal volumes for the same states were $0.66 \pm$ $0.04,0.53 \pm 0.02,0.20 \pm 0.01$ and $0.15 \pm 0.02$ litres. Breathing frequencies were $12 \pm 1,13 \pm 1$, $18 \pm 1$ and $20 \pm 2$ breaths per minute. Enflurane anaesthesia consistently produced an unique pattern of inspiratory flow (Figure 2). Sedation did not alter $\mathrm{PET}_{\mathrm{CO}_{2}}$ or $\mathrm{PaCO}_{2}$; anaesthesia (1.1 MAC) increased both and produced an arterial to endtidal $\mathrm{PCO}_{2}$ difference of $0.9 \mathrm{kPa}$ (7 torr) (Table I).

At enflurance 1.5 MAC, there was a profound and somewhat variable depression of ventilation, with the result that it was difficult to be certain of steady anaesthetic and respiratory states. Thus, we can report values of $\mathrm{Pa}_{\mathrm{CO}_{2}}$ and chemoreflex activity for one dose of anaesthesia (I.I MAC) only.

Accompanying the reduction in ventilation during sedation and anaesthesia there was a dose-related impairment of the carbon dioxide response slope (Table I, Figure 3) and doserelated and marked depression of the reflex response to hypoxaemia (Table I. Figure 4). Sedation reduced both indices of response 10 hypoxaemia to less than one half of awake values

FIGURE I Inspired ventilation and its components, tidal volume and breathing frequency (breaths/minute). of subjects awake and at three doses of enflurane -0.1 , 1.1 and 1.5 MAC. Values depicted are means \pm S.E.M. Data representing the awake state are those of the sedated group of subjects only.
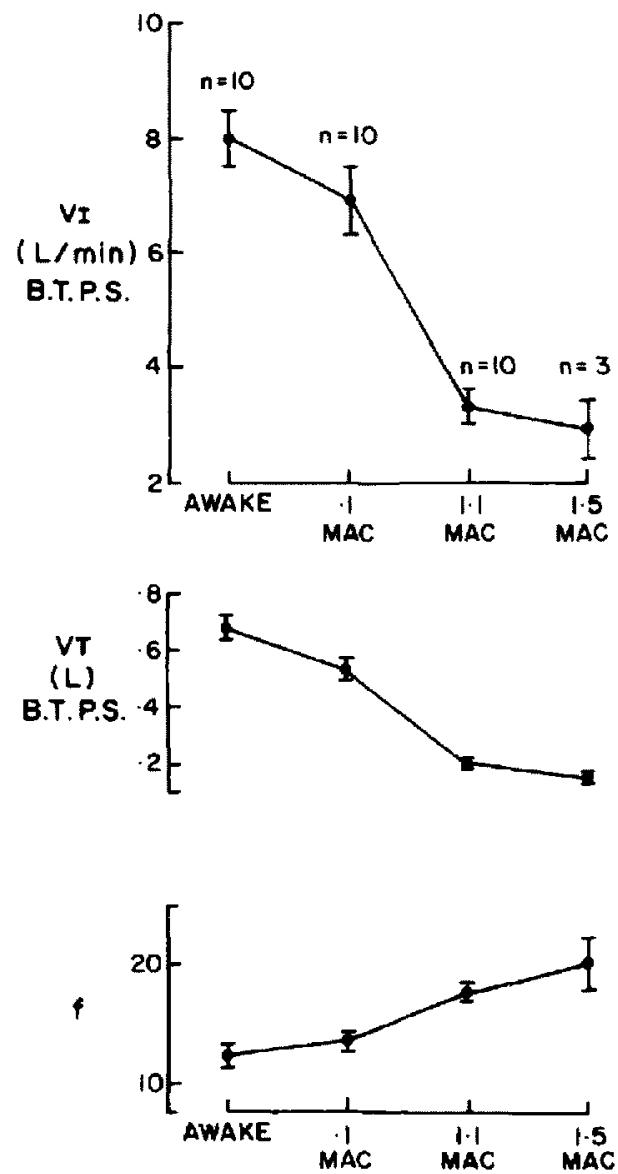


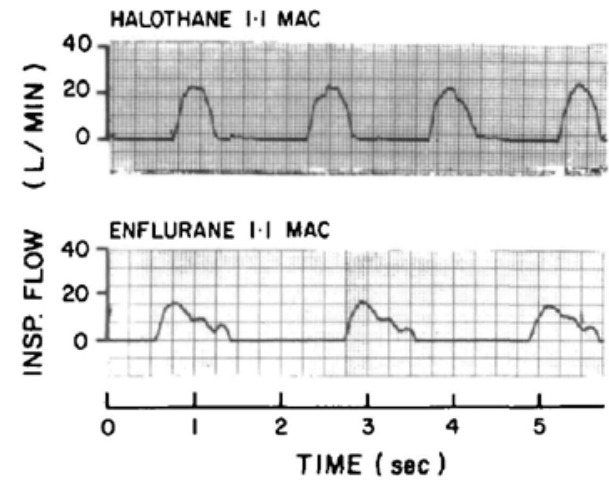

Figurt 2 Comparison of inspiratory flow patterns of a subject anaesthetized with halothane 1.1 MAC and another anatesthetized with enflurane 1.1 MAC. During halothane anaesthesia there was the usual sinusoidal pattern of inspiratory flow. Enflurane typically caused a slower and somewhat variable deceleration from peak inspiratory flow. Note that the slower respiratory frequency associated with enflurane was due to prolongation of both inspiratory and expiratory phases.

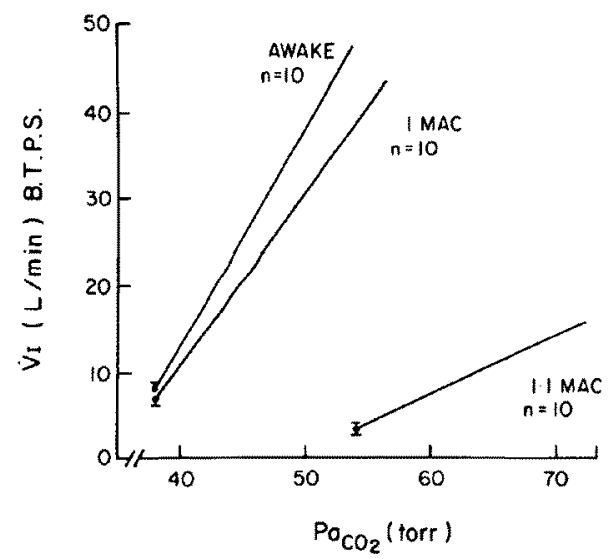

FIGURE 3 Ventilatory responses to carbon dioxide of subjects awake and at enflurane $0.1 \mathrm{MAC}$ and 1.1 $M A C$. Dots represent mean values of ventilation (with S.E.M.) at mean resting $\mathrm{Paca}_{2}$. Lines depicting mean slopes of ventilation: $\mathrm{PCO}_{2}$ relationships extend from the resting points. The alwake state is represented by data collected from the sedated group of subjects only.

and anaesthesia nearly abolished them. Due to the intolerance of most awake subjects to the magnitude of hypercarbia which had been present during their anaesthetic, we failed to compare awake and anaesthetic values of ventilation and response to hypoxaemia at the same level of $\mathrm{Pa}_{\mathrm{CO}_{2}}$ (Table 1).

The response to doxapram of four subjects

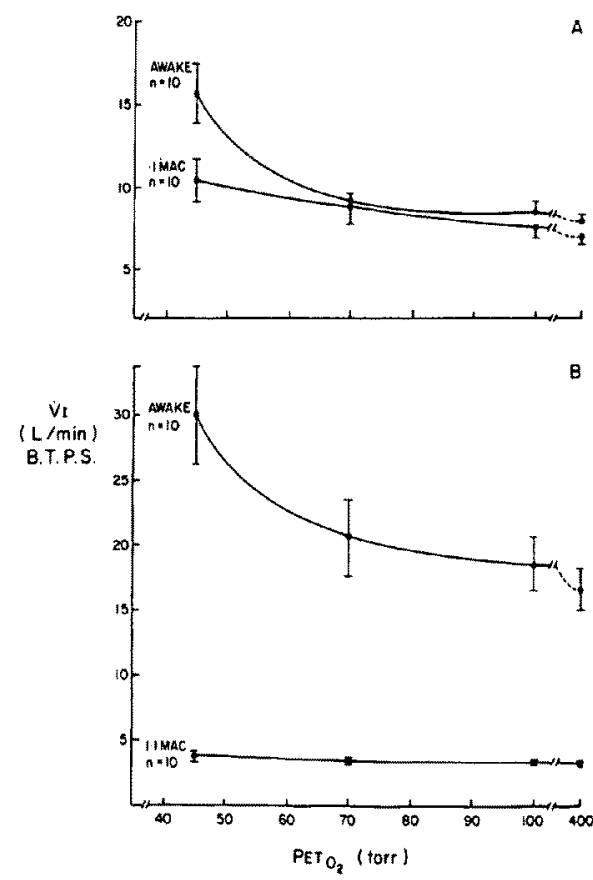

FIGURE 4 Ventilatory responses to isocapnic hypoxaemia during $(A)$ enflurane sedation $(0.1 \mathrm{MAC})$ and $(B)$ enflurane anaesthesia (1.1 MAC), along with their awake controls. Each response is represented by mean values of ventilation ( \pm S.E.M.) at $\mathrm{Pt.T}_{0_{2}} 53.2$. 13.3.9.3 and 6.0 kPa (400, 100, 70 and 45 tom $)$ and lines hand drawn through these points. Sedation and awake data were collected at an identical mean $\mathrm{Pa}_{\mathrm{C}_{2}} .5 .1 \mathrm{kPa}$ ( 38 torr), but antesthesia and awake responses were at markedly different $\mathrm{Pa}_{\mathrm{CO}_{2}}, 7.2$ and $5.7 \mathrm{kPa}$ (54 and 43 torr) respectively.

while sedated was $5.9 \pm 2.7 \mathrm{1} / \mathrm{min}$ (mean \pm S.E.M.). compared to $16.4 \pm 3.3 \mathrm{l} / \mathrm{min}$ while awake $(p<0.05)$. The same response of three anaesthetized subjects was only $0.7 \pm 0.21 / \mathrm{min}$ (mean \pm S.E.M.), a value markedly less than when awake $(15.9 \pm 2.31 / \mathrm{min}) \mathrm{p}<0.02)$.

To compare the activity of each chemoreflex during sedation and anaesthesia (that is at 0.1 and 1.1 MAC), we constructed a bar diagram depicting the responses in each state as a percentage of control or awake (see Figure 5). The response to carbon dioxide was represented by the slope of the ventilation: $\mathrm{PCO}_{2}$ relationship, the response to hypoxaemia by the $\Delta \dot{V}_{1_{45}}$ and the response to doxapram by the maximum increment in instantaneous ventilation. The diagram illustrates that sedation and anaesthesia had a more potent impact on response to hypoxaemia and doxapram (sedation $p<0.05$; anaesthesia $p<0.01$ ). 


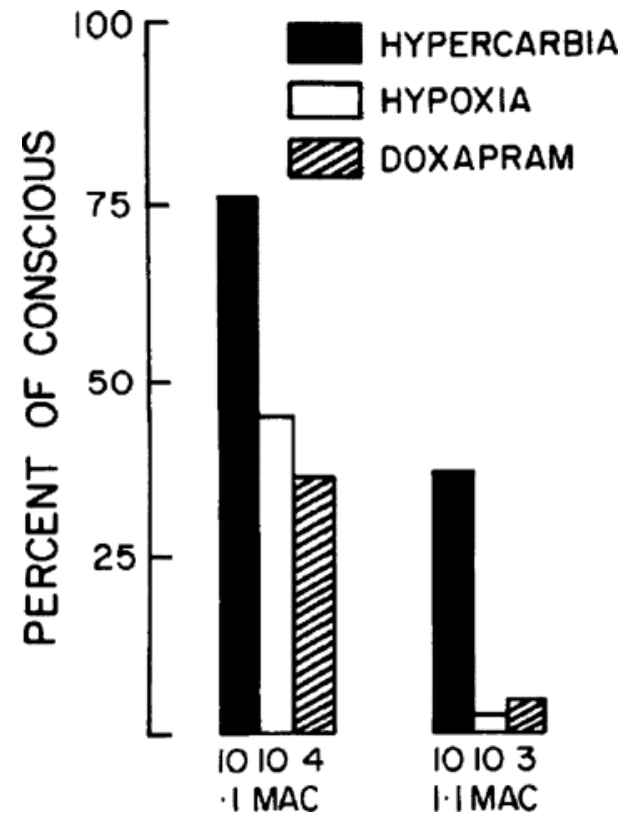

Fygure 5 The relative activity of each chemoreflex tested at enflurane 0.1 MAC and I.I MAC. expressed as a per cent of awake. The index used to represent each reflex is stated in the text. Sedation and annesthesia reduced all three responses and particularly those to hypoxiemia and doxapram. Note that during anies. thesia, the response to hypoxaemia was nearly abolished.

\section{Discussion}

Like halogenated anaesthetic agents in general in man, enflurane reduces total and alveolar ventilation and alters the pattern of breathing to small volumes and increased frequencies. ${ }^{1.2 .12 .13}$ Its overall ventilatory impact is profound. In light andesthetic concentrations without surgical stimulation, enflurane frequently increases $\mathrm{Paco}_{2}$ to $8.0 \mathrm{kPa}$ (60 torr) or more. ${ }^{3}$ The purpose of this work was to describe the impact of enflurane on central and peripheral chemoreflexes fundamental to regulation of breathing. the ventilatory responses to hypercarbia and isocapnic hypoxaemia.

Experimental conditions in our study were identical for awake and sedated states; subjects sat in a chair, breathed through a mouthpiece and were eucapnic. However. there were several added variables during anaesthesia. Anaesthetized subjects were supine, their tracheas were intubated, they had received thiopentone during induction and $\mathrm{PaCO}_{2}$ was increased (Table 1). We doubt that these additional factors reduced the significance of the differences observed between the awake and anaesthetized states. The supine position does not influence ventilation or the response to carbon dioxide in the awake state: 14 our dose of thiopentone ( 1 to $2 \mathrm{mg} \cdot \mathrm{kg}^{-1}$ ) has no discernible effect on ventilatory control; 15 tracheal intubation with an $8 \mathrm{~mm}$ or $9 \mathrm{~mm}$ orotracheal tube does not alter chemoreflex activity during light halothane anaesthesia: ${ }^{4}$ and difference in $\mathrm{PCO}_{2}$ between the awake and anaesthetized states would only underestimate the impact of enflurane on the isocapnic responses to hypoxaemia. ${ }^{\mathrm{B}}$

To compare ventilation and ventilatory refiexes, we wished to study reasonably steady and definable states, with respect to respiratory variables and enfurane effect. We defined a "steady-state" as constant values of end-tidal carbon dioxide and end-tidal enfurane over at leașt ten minutes during which both inhaled enflurane concentration and minute ventilation were unchanged. "Steady-states" were achieved quickly in awake subjects and after approximately 20 and 45 minutes of enflurane inhalation in sedated and anaesthetized subjects respectively. The longer period to stabilize the anaesthetic state was made necessary by hypoventilation and the higher levels of carbon dioxide.

We employed steady end-tidal concentrations of enflurane, converted to multiples of MAC, as estimates of enflurane dose. Our assumed value of 1.68 per cent for MAC may not be precise for healthy 20 - to 30-year-old subjects.* However, a small error in MAC value would not invalidate the interpretations which follow.

In agreement with Calverley, et al., we found that enflurane 1.0-1.1 MAC causes greater reduction in ventilation and elevations of $\mathrm{Pa}_{\mathrm{CO}_{2}}$ than equi-anaesthetic concentrations of halothane, ${ }^{4.17}$ methoxyflurane ${ }^{18}$ or isoflurane. ${ }^{19}$ At enflurane doses above 1.5 MAC. subjects rapidly become totally apnoeic. Not unexpectedly, surgical stimulation considerably attenuates this ventilatory depressant effect; ${ }^{20}$ when surgery is instituted early in the course of an enflurane anaesthetic, $\mathrm{PaCO}_{2}$ may even be normal. 21 It is

${ }^{*}$ Calverley assumed the MAC values for young adults to be 1.86 per cent: ${ }^{3}$ our recent unpublished observations of ten 20- to 30-year-old subjects equilibrated with enfurane for one hour suggest a $M A C$ value of 1.55 per cent. 
interesting that a lengthy ( 7 hour) exposure to enflurane also attenuates ventilatory depression. ${ }^{3}$

Comparing 1.1 MAC doses of enflurane and hothane. ${ }^{4}$ we noted that, notwithstanding the greater ventilatory depression with enflurane, tidal volumes with each agent were very similar. Calverley. et al. observed the same..$^{3}$ The lesser rate of breathing with enflurane was due to longer inspiratory and expiratory times, the former coupled with a unique pattern of inspiratory flow with a mure gradual and variable deceleration from peak flow (Figure 2). (The mechanisms of flow profiles and respiratory cycle timing are not understood in man, either awake or anaesthetized. ${ }^{22}$ )

To test the dominant reflex in normal metabolic regulation of ventilation. the "central" or medullary chemoreceptor mediated response to carbon dioxide $\left(\mathrm{H}^{+}\right)$, we increased carbon dioxide levels in our subjects by the Read rebreathing technique. This method maintains a constant relationship between the "measured" stimulus (change in circuit carbon dioxide) and the "actual" stimulus (change in medullary tissue carbon dioxide). ${ }^{7}$ despite variations in cerebral blood flow, cerebral blood flow response to carbon dioxide and cerebral metabolic rate, all of which accompany anaesthesia. ${ }^{23}$ On this basis. we believe the Read technique to be preferred over conventional steady-state methods for studying the impact of anaesthesia on the carbon dioxide response. Like other halogenated hydrocarbons, ${ }^{17.18}$ enflurane displaced the carbon dioxide response curve to the right and diminished its slope, in a dose-related fashion (Table I. Figure 3).

The "peripheral" chemoreceptor reftex system, with receptors located in carotid bodies, plays only a minor role in the normal metabolic regulation of ventilation, but mediates the whole ventilatory response to both acute hypoxaemia and moderate metabolic acidaemia. To test this system, we exposed subjects to a controlled period of isocapnic hypoxaemia and a dose of doxapram believed to drive ventilation by an action on peripheral chemoreceptors alone.9.24 The limitations of our methods have been previously described; 4 in particular, it is to be noted that hypoxaemic tests were progressive and brief and that results cannot necessarily to extrapolated to lengthier hypoxaemic stresses. Enflurane anaesthesia (1.1 MAC) nearly abolished reflex responses to both hypoxaemia and doxapram and sedation reduced them to less than half of awake responses (Table I. Figure 4). These responses mediated by peripheral chemoreceptors were impaired more than the central carbon dioxide $\left(\mathrm{H}^{+}\right)$response (Figure 5) and, in that respect, enflurane was similar to halothane. ${ }^{4}$ Furthermore, during both enflurane and halothane anaesthesia, hypoxaemia produced an identical change in pattern of breathing - smaller tidal volumes and increased breathing rates. During halothane, the hypoxaemia-induced reduction in tidal volume was due to a selective loss in the contribution of rib-cage expansion; $;^{25}$ whether enflurane has the same effect is not known. Possible mechanisms of selective anaesthetic effects on peripheral chemoreceptor-mediated reflexes were described in our previous report.

We are aware of one previous study of the impact of enflurane on ventilatory chemoreflex in awake and anaesthetized dogs. ${ }^{26}$ Enflurane reduced responses to both hypercarbia and hypoxaemia, but there was no apparent selective effect on either. It is interesting that the same species-related difference exists between man and dogs anaesthetized with halothane. ${ }^{4}$

A number of observations support our contention that inhalation anaesthetics are not simply non-specific ventilatory depressants in man, but have selective and potent actions on particular mechanisms of breathing control. Halothane disproportionately impairs several peripheral chemoreceptor medialed reftexes, the responses to hypoxaemia, ${ }^{4}$ hyperoxaemia, ${ }^{27}$ low dose doxapram, ${ }^{4}$ peripheral chemoreceptor mediated hypercarbia, ${ }^{27}$ metabolic acidaemia ${ }^{28}$ and acidaemic-hypoxaemic interaction. ${ }^{28}$ The present work indicates a similar effect of enflurane on responses to hypoxaemia and low-dose doxapram. Another ventilatory reflex, the nonchemically mediated response to mechanical loading, is selectively depressed by methoxyflurane. ${ }^{29}$ Light halothane anaesthesia may reduce overall ventilation by an isolated effect on the rib-cage contribution to ventilation, leaving the diaphragm contribution unaffected; ${ }^{30}$ light methoxyflurane anaesthesia may reduce ventilation by selectively increasing the impedance of the ventilatory pump, leaving neuromuscular drive to breathe unimpaired. ${ }^{29}$ Taken together, these observations suggest several selective actions of halogenated anaesthetics on the numerous reflexes involved in control of breathing in man.

Clinical implications of the present work relate only to the conditions studied; that is, to fit young subjects inhaling enfiurane to steady anaesthetic 
states, without surgical stimulation. The potential implications of reduced alveolar ventilation are well known; these are hypercarbia, hypoxaemia and delayed induction and emergence from anaesthesia. The latter may explain the recent observation that, despite a lower blood-gas solubility coefficient, rates of induction and emergence may be no more rapid with enfurane than with halothane. ${ }^{31}$ A reduced ventilatory response to added carbon dioxide implies a reduced ability to compensate for inhaled carbon dioxide with increased $\mathrm{Pa}_{\mathrm{CO}_{2}}$ at a given $\mathrm{Fi}_{\mathrm{CO}_{2}}$, whether the inhaled carbon dioxide originates exogenously or endogenously, as by rebreathing. An absent ventilatory response to hypoxaemia means loss of a vigorous homeostatic mechanism which normally defends arterial oxygenation.

\section{SUMMARY}

Enflurane sedation and anaesthesia in healthy fit subjects reduced ventilation and the response to carbon dioxide. hypoxaemia and a low dose of doxapram, all in a dose-related fashion. Comparing the three chemoreflexes tested, the response to hypoxaemia and doxapram were the more profoundly impaired; they were nearly totally abolished by andesthesia. These effects of enflurane on chemoreflex activities are qualitatively similar to those previously observed with halothane.

\section{RÉSUMÉ}

L'enfiurane à concentrations sédatives et anesthésiques produit une diminution de la ventilation et déprime la réponse réflexe à l'hypercarbie, à l'hypoxémie ainsi que celle à une petite dose de doxapram, le tout de façon proportionnelle à la concentration inhalée. Ce sont les réflexes à l'hypoxie et au doxapram qui sont les plus touchés: ils sont pratiquement abolis par l'anesthésie à l'enflurane. Ces effets sont qualitativement similaires à ceux observés avec Ihalothane

\section{ACKNOWLEDGEMENTS}

The authors wish to thank the subjects who participated in this study, Drs. C. Rorabeck, R.I. Brooke, and I.D.F. Schofield for agreeing to the participation of their patients in this study and to Mrs. L. Nolan for manuscript lyping.

\section{ABBREVIATIONS}

$\dot{V}_{I} \quad$ inspired minute ventilation

VT inspired tidal volume

f frequency of breathing (breaths $/ \mathrm{min}$ )

$\left[\mathrm{H}^{+}\right] \mathrm{a}$ arterial hydrogen ion activity

$\mathrm{PaCO}_{2}$ arterial carbon dioxide tension

$\mathrm{PET}_{\mathrm{CO}_{2}}$ end-tidal carbon dioxide tension

$\mathrm{PET}_{\mathrm{O}_{2}}$ end-tidal oxygen tension

$\Delta \dot{V}_{1} \quad$ change of inspired minute ventilation

$\Delta \dot{V}_{I_{45}} \quad$ isocapnic change of inspired minute ventilation from hyperoxia to a PET/2 of $6.0 \mathrm{kPa}$ (45 torr)

"A" calculated variable of hypoxic responsiveness (see MeTHods)

$\mathrm{FI}_{\mathrm{CO}_{2}}$ fractional concentration of inspired carbon dioxide

B.T.P.S. body temperature and ambient pressure saturated with water vapour

S.D. standard deviation

S.E.M. standard error of the mean

\section{REFERENCES}

1. Lebowitz. M.H.. Blitt. C.D. \& Dillion. J.B. Clinical investigation of compound 347 (Ethrane). Anesth. \& Analg. 49: I (1970).

2. VirTue, R.W., LUND. L.O., Phelips. M., JR., VoGel, J.H.K. BECKWITT, H. \& HERON. M. Difluoromethyl 1.1,2-trifluoro-2-chloroethyl ether as an aniesthetic agent. Can. Anaes, Soc. J. 13(3): 233 (1966).

3. Calverley. R.K.. Smith. N.T.. Jones. C.W.. Prys-Roberts. C. \& Eger. E.I. Ventilatory and cardiovascular effects of enflurane anesthesia during spontaneous ventilation in man. Anesth. \& Analg. 57: 610 (1978).

4. KNILL. R.L. \& GELB. A.W. Ventilatory responses to hypoxia and hypercapnia during halothane sedation and anesthesia in man. Anesihesiology 49: 244 (1978).

5. COOPER, E.A. \& SMITH. N. Indirect estimation of arterial $\mathrm{PCO}_{2}$. Anaesthesia 16: 445 (1961).

6. READ. D.J.C. A clinical method for assessing the ventilatory response to $\mathrm{CO}_{2}$. Australasian Ann. Med. 16: 20 (1967).

7. READ. D.J.C. \& Leigh, J. Blood-brain tissue $\mathrm{Pro}_{2}$ relationships and ventilation during rebreathing. J. Appl. Physiol. 23: 53 (1967).

8. Weil. J.V.. BYrne-Quinn, E., Sodal. I.E., FRIESEN. W.O.. UNDERHILL. B.. FILLEY. G.F.\& GROVER. R.F. Hypoxic ventilatory drive in normal man. J. Clin. Invest. 49: 1061 (1970).

9. Severinghaus. J. Ozanne. G. \& Massuda, y. Measurement of the ventilatory response to hypoxia. Chest $70: 121$ (1976).

10. Gelb. A.W. \& KNILL. R.L. Subanaesthetic halothane: its effect on regulation of ventilation and relevance to the recovery room. Canad. Anaesth. Soc. J. 25(6): 488 (1978).

11. Manninen, P. \& Knill. R.L. Cardiovascular signs of acute hypoxaemia and hypercarbia during 
enflurame and halothane anaesthesia in man. Canad. Anaesth. Soc. J. 26: 282 (1979).

12. Hilrich. M. \& Cascokbi. H.F. Crossover study of Ethrane and halothane in volunteers. Anesthesiology 3/(4): 370 (1969).

13. Dobkin. A.B., Nishioka. K., Gengaje. D.B., Kim. D.S., Evers. W. \& Israfi. J.S. Ethrane (compound 347) anesthesiti. Anesth. \& Analg. 48(3): 477 (1969)

14. RigG.J.R.A.. RebuC'K. A.S. \& CAMPBell. E.J.M. The effect of posiure on the ventilatory response to $\mathrm{CO}_{2}$. J. Appl. Physiol. 37: 487 (1974).

15. KNIL.L. R.L.. BRighi. S. \& Manninen. P. Hypoxic ventilatory responses during thiopentone sedation and anaesthesia in man. Canad. Anaesth. Soc. J. 25(5): 366 (1978).

16. Glon. H. \& Saidman, L.J. The minimum atveolar concentration of enflurane in man. Anesthesiology 35(4): 361 (1971).

17. Munson. E.S., Larson. C.P.. Jr.. Babad. A.A., Rt:GaN. M.J.. Butchti.. D.R. \& Egt.R. E.I. The effects of haluthane. fluroxene and cyclopropane on ventilation. Anesthesiology 27(6): 716 (1966).

18. Larson, C.P., JR.. EGitr. E.I., Muallem, M. Butchi:L. D.R.. Munson. E.S. \& EISELE. J.H. The effecls of diethyl ether and methoxyflurane on ventilation. Anesthesiology 30(2): 174 (1969).

19. Fourcadt. J.E. Sitivins. W.C.. Larson. C.P. JR. Cromwell. T.H., Bahiman, S.H., HickeY. R.F.. HALSEY, M.J. \& EGER. E.I. The ventilatory effects of Forane, a new inhaled anesthetic. Anesthesiology 35(1): 26 (1971).

20. BuURKE.D.L.. Rost.net.RG.D.M.D. \& ToBias. R. Effect of surgical stimulation on respiration during anaesthesia. Abstracts of Scientific Papers. ASA Meeting 51 (1978).

21. Botry C. Brown. B.. Stanitey, V. \& StrPHeN. C.R. Clinical experiences with compound 347 , a halugenated anesthetic agent. Anesth. \& Analg. 47(5): 499 ( $(1968)$.
22. Paksin, S., Skovsted, P. \& Smith, T.C. Failure of the Hering-Breuer reflex to account for tachypnea in anesthetized man. Anesthesiology 29:550 (1968).

23. Alexander, S.C. Wollman, H. Cohte, P.J., Chase, P.E. \& Behar, M. Cerebrovascular response to $\mathrm{Pa}_{\text {Co }}$ during halothane anesthesia in man. J. Appl. Physiol. 19: 561 (1964).

24. Kaufman. R.D. Personal communication. November 1976

25. KNILL, R.L., Clement, J.L. \& Gele, A.W. Ventilatory responses mediated by peripheral chemoreceplors in anaesthetized man. Advances in Experimental Medicine and Biology 99:67 (1978).

26. Hirshman, C.A., McCullough, R.t. Cohen, P.J. \& WEIL. J.V. Depression of hypoxic ventilatory response by halothane. enflurane and isofurane in dogs. Brit. J. Antaesth. 49 : 957 (1977).

27. Duffin. J.. Triscott. A.\& Whitwam, J.G. The effect of halothane and thiopentone on ventilatory responses mediated by the peripheral chemoreceptors in man. Brit. J. Anaesth. 48: 975 (1976).

28. Knill, R. Chung, D. \& Basktrvilit. J. Ventilatory responses to acute "Iso- $\mathrm{PCO})_{2}^{*}$ acidosis in awake and anaesthetized man. Clinical Research 26(6): $879 \mathrm{~A}(1978)$.

29. Direnne, J.P.. Couture, J. Iscol., S.. Whitt.Law. W.A. \& Milic-Eall.., J. Oeclusion pressures in men rebreathing $\mathrm{CO}_{2}$ under methoxyflurane anesthesia. J. Appl. Physiol. 40(5): $805(1976)$

30. Tusiewiez. K., Bryan. A.C. \& Frot.si. A.B. Contributions of changing rib-cage-diaphragm interactions to the ventilatory depression of halothane anesthesia. Anesthesiology 47: 327 (1977).

31. StEward, D.J. A trial of enflurane for pacdiatric out-patient anaesthesia. Canad. Anaesth. Soc. J. $24: 603$ (1977). 